\title{
Linking Availability Expectations, Bidirectional Boundary Management Behavior and Preferences, and Employee Well-Being: an Integrative Study Approach
}

\author{
Kathrin Reinke ${ }^{1,2} \circledast$. Gisela I. Gerlach ${ }^{3}$ \\ Accepted: 25 August 2021 / Published online: 5 October 2021 \\ (c) The Author(s) 2021, corrected publication 2021
}

\begin{abstract}
Information and communication technologies enable employees to be available anywhere and anytime, raising availability expectations of work and nonwork contacts. Building on the theory of planned behavior and the person-environment fit theory, the present study examines how others' availability expectations predict employees' management of work and nonwork boundaries, and how these bidirectional boundary management behaviors relate to well-being. Results of structural equation modeling with data from 401 employees collected in two waves show that availability expectations of both coworkers and nonwork contacts predict how employees manage the boundaries of work and nonwork domains. Thereby, availability expectations are negatively related to segmentation of the two domains and coworkers' expectations show an indirect effect on employee well-being. Further, our study shows that work-nonwork and nonwork-work segmentation behavior have divergent effects on employee well-being, indicating that asymmetric boundary management behavior with high work-nonwork segmentation and low nonwork-work segmentation may be beneficial. Besides, moderation analyses underline the importance of enabling individuals to align their boundary management preferences with their actual behavior, especially when individuals have high work-nonwork segmentation preferences. By integrating and unveiling distinct antecedents of work-nonwork and nonwork-work segmentation behavior and their divergent effects on well-being, the present study contributes to a comprehensive framework for investigating and understanding bidirectional boundary management in the face of technology-enabled availability.
\end{abstract}

Keywords Information and communication technology (ICT) - Availability expectations $\cdot$ Boundary management $\cdot$ Life balance $\cdot$ Employee well-being

\section{Introduction}

Employees are managers of the boundaries of their life domains, shaping the flexibility and permeability of the boundaries around work and nonwork domains (Ashforth et al., 2000). In today's working world, an important aspect of how employees manage the boundaries between work and nonwork is their handling of technology-assisted availability

Kathrin Reinke

kathrin.reinke@tu-darmstadt.de

1 Institute of Psychology, Technische Universität Darmstadt, Darmstadt, Germany

2 Department of Business Psychology, University of Kassel, Kassel, Germany

3 Department of Economics, Universität Koblenz-Landau, Landau, Germany
(Sayah, 2013). That is, information and communication technologies (ICTs) enable employees to stay connected with work contacts off the job, for example, by engaging in work-related email communication after hours (Braukmann et al., 2018). This extended availability fosters flexibility and permeability of the nonwork boundary, and thus integration of work into nonwork domains (Ashforth et al., 2000; Boswell \& Olson-Buchanan, 2007). The vast majority of research on consequences thereof provides evidence for detrimental effects on employee well-being, as reflected, for example, in increased work-life conflict and impaired recovery (e.g., Boswell \& Olson-Buchanan, 2007; Park et al., 2011). However, isolatedly studying the phenomenon of integrating work into nonwork domains implies studying only "one side of the coin," as transitions between work and nonwork may occur in both directions (Clark, 2000; Kossek $\&$ Lautsch, 2012). Likewise, ICTs not only allow employees to be available for work contacts in nonwork domains but 
also to stay connected with nonwork contacts in the work domain (Sayah, 2013), for example, by taking phone calls from family members at work. This facilitates the integration of nonwork matters into work.

Moreover, employees might manage their work and nonwork boundaries differentially, particularly through a differentiated use of ICTs. For example, employees can use their smartphone to be available for nonwork contacts during work but turn off a company-supplied smartphone after hours to stop work-related communication from entering nonwork domains (Kossek \& Lautsch, 2012). Or conversely, employees can avoid dealing with nonwork matters at work by turning off push notifications for nonwork communication but turn on push notifications for workrelated communication after hours. Yet, studies on boundary management enactment often focus on work-nonwork segmentation behavior (i.e., the degree to which individuals actually segment work from nonwork domains), omitting nonwork-work segmentation behavior (i.e., the degree to which individuals actually segment nonwork from work) (e.g., Kubicek \& Tement, 2016; Palm et al., 2020). Hence, although well-established in theory (Clark, 2000; Kossek \& Lautsch, 2012), the bidirectional nature of boundary management behavior is often disregarded. This limitation is especially apparent in research on boundary management in the context of ICT-enabled availability (e.g., Derks et al., 2016; Piszczek, 2017). Studying only one side of the coin yet bears the risk of overrating the effects of this side, building incomplete theory, and developing research frameworks that omit potential differences in the antecedents and outcomes of work-nonwork and nonwork-work segmentation behavior (Kossek \& Lautsch, 2012; Wayne et al., 2020). To overcome limitations of previous research, the present study takes an integrative approach, capturing employees' bidirectional work-nonwork and nonwork-work segmentation behavior, and investigating their differential antecedents and effects on employee well-being.

Our study contributes to research on the work-nonwork interface in several ways. First, we aim to enrich our understanding of the factors that shape how individuals manage the boundaries of work and nonwork domains in the age of ICT-enabled availability. With ICTs on the rise, it is crucial to study the impact of expectations and norms involved with the unlimited possibilities of communicating across boundaries, while accounting for the effects of other, wellestablished antecedents of boundary management behavior. As recommended by Matthews et al. (2016), we draw on the theory of planned behavior (Ajzen, 1991; Fishbein and Ajzen, 2010) to identify relevant categories of antecedents of boundary management behavior. Specifically, we argue that individuals' boundary management behavior should not only be influenced by their personal attitudes toward and their perceived control over their boundary management behavior (e.g., Kossek et al., 2012; Matthews et al., 2010; Powell \& Greenhaus, 2010), but also by subjective norms regarding boundary management, i.e., perceived social pressure to engage or not to engage in segmentation behavior (Ajzen, 1991). Since ICTs enable communication without temporal and spatial boundaries, expectations to be available across life domains have increased, changing subjective norms of the extent to which one should be available (Derks et al., 2015; Piszczek, 2017). We refer to this phenomenon as availability expectations, which reflect the degree to which an individual perceives that members of one domain demand the individual to be available via ICTs while he or she is engaged in another domain. The few studies that investigated the effects of availability expectations on boundary management behavior mainly focused on condensed availability expectations of work contacts, i.e., organizational expectations (e.g., Fenner \& Renn, 2010; Piszczek, 2017). The present study takes a more differentiated approach, distinguishing supervisor, coworker, and nonwork contact availability expectations, and examines their respective relationships with individuals' boundary management behavior. As research has shown that individuals might perceive significant differences between availability expectations of different social groups (Mazmanian, 2013), we consider it important not to lump expectations of supervisors, coworkers, and nonwork contacts together. Moreover, individuals might attribute distinct importance to the three groups' availability expectations and consequently, react differently to them, depending on the consequences they face when satisfying or violating them. As a result, the three groups' availability expectations might affect work-nonwork and nonwork-work segmentation to a different degree. Thus, we investigate the three groups' availability expectations simultaneously as drivers of bidirectional boundary management behavior, while accounting for other well-established antecedents.

Second, we integrate and extend knowledge on the potentially differential relationships of work-nonwork and nonwork-work segmentation behavior with employee wellbeing. Since well-being is an important predictor of jobrelated outcomes such as performance and turnover intention (Wright \& Huang, 2012), investigating how boundary management behavior relates to employee well-being could provide organizations with important implications for their occupational health management. Prior studies indicate that segmentation is more beneficial for well-being as opposed to "boundary blurring" (Kubicek \& Tement, 2016; Wepfer et al., 2018). Yet, with its focus on work-nonwork segmentation, preceding research leaves unclear whether these insights are transferable to nonwork-work segmentation. Instead, we simultaneously examine the well-being outcomes of both work-nonwork and nonwork-work segmentation behavior. Further, prior research primarily investigated 
indicators of well-being that are closely related to the work-nonwork interface, such as work-nonwork conflict or enrichment (e.g.Kubicek \& Tement, 2016; Matthews et al., 2010; Powell \& Greenhaus, 2010). In this study, we examine more global indicators of employee well-being that are not domain-specific or directional. Thereby, we aim to unveil whether and how both work-nonwork and nonworkwork segmentation behavior contribute to general employee well-being.

Third, we aim at enhancing our understanding of the conditions under which work-nonwork and nonwork-work segmentation behavior are related to increased or impaired well-being. While the majority of research finds beneficial effects of segmentation behavior on well-being (e.g., Matthews et al., 2010; Park et al., 2011; Wepfer et al., 2018), we argue that the outcomes of work-nonwork and nonwork-work segmentation should depend on individuals' boundary management preferences. Although the potentially moderating role of boundary management preferences is well-embedded in the person-environment (P-E) fit approach to the worknonwork interface (Edwards \& Rothbard, 1999; Kreiner, 2006), boundary management preferences were primarily examined and confirmed as predictors of boundary management behavior (e.g., Methot \& LePine, 2016; Palm et al., 2020; Powell \& Greenhaus, 2010) or as part of the preferences-supplies fit (e.g., Basile \& Beauregard, 2021; Bogaerts et al., 2018). The few studies investigating the moderating role of boundary management preferences for the effects of actual boundary management behavior are limited in that they focus on work-nonwork segmentation, and its effects on work-life conflict (Derks et al., 2016; Gadeyne et al., 2018). With this study, we aim to add to insights of prior research by investigating whether work-nonwork and nonwork-work boundary management preferences moderate the relationships between individuals' bidirectional boundary management behavior and their well-being.

Together, our study complements existing research by adding to a more holistic, but likewise thorough understanding of why individuals engage in certain boundary management behaviors, and how these relate to employee well-being. Investigating both work-nonwork and nonworkwork segmentation behaviors, their differential antecedents, as well as their distinct effects on employee well-being, this study integrates various constructs into a comprehensive framework that were often examined in isolation or discussed in theoretical considerations (Kossek \& Lautsch, 2012; Wayne et al., 2020). Since a theoretical process model on differential antecedents and outcomes of boundary management is yet to be developed, we draw on principles from two theories, which are suggested to provide valuable theoretical frameworks for research on the worknonwork interface (Matthews et al., 2016): the theory of planned behavior (Ajzen, 1991; Fishbein and Aijzen 2010) to organize and examine antecedents of boundary management behavior and the P-E fit approach to the work-nonwork interface (Edwards and Rothbard 1999; Kreiner, 2006) to explain how different boundary management behaviors may contribute to employee well-being. With this theoretical foundation, we develop and investigate a research framework that adds to our understanding of the mechanisms of employees' boundary management in the age of ICT-enabled availability. We test the research framework with data from 401 employees collected at two points in time. Our results provide employees and organizations with levers for avoiding undesired consequences and fostering positive effects of boundary management.

\section{The Concept of Bidirectional Boundary Management Behavior}

According to boundary theory, individuals create and manage boundaries around work and nonwork domains (Ashforth et al., 2000; Nippert-Eng, 1996). These boundaries can be described in terms of their flexibility, that is, the degree to which they are elastic and can be temporally or spatially changed, and their permeability, that is, the extent to which they allow elements of one domain to enter the other (Ashforth et al., 2000). Depending on the degree of flexibility and permeability, boundary management of life domains can be arrayed on a continuum from segmentation to integration (Ashforth et al., 2000). Segmentation implies rather inflexible and impermeable boundaries, with transitions between work and nonwork domains requiring some effort by the individual, whereas integration is characterized by flexible and permeable boundaries that allow individuals to transit easily between domains (Ashforth et al., 2000; Nippert-Eng, 1996).

Individuals are suggested to vary regarding the degree to which they prefer to and actually do segment or integrate work and nonwork domains. "Segmenters" prefer clear, thick boundaries around work and nonwork domains, while "integrators" prefer flexible and permeable boundaries (Ashforth et al., 2000; Nippert-Eng, 1996). Extending these notions, Clark (2000) and Kossek and Lautsch (2012) suggest that the flexibility and permeability of the work and nonwork boundaries can diverge, that is, individuals may prefer to and actually manage these boundaries asymmetrically. For example, individuals may have a flexible and permeable boundary around nonwork domains, but a clear and thick boundary around the work domain, such that transitions from work to nonwork are easier and occur more frequently than transitions from nonwork to work. Hence, boundary management is a bidirectional phenomenon (Hecht \& Allen, 2009; Kossek \& Lautsch, 2012), requiring consideration of directionality of boundary management preferences and behavior. Accordingly, the present study differentiates between 


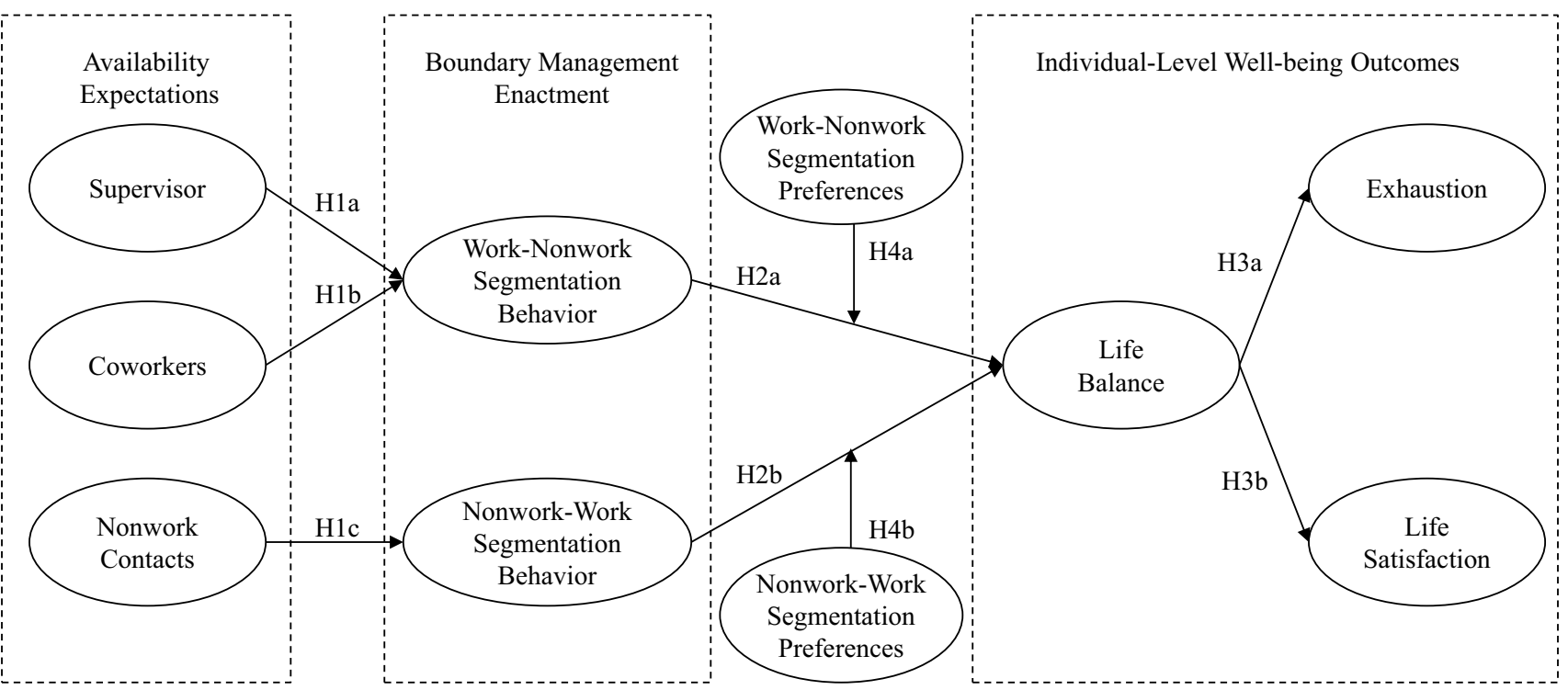

Fig. 1 Conceptual research model with hypothesized relationships

work-nonwork segmentation and nonwork-work segmentation behavior and examines their differential antecedents and discrete effects on employee well-being. To develop our research model, the present study integrates key concepts of the theory of planned behavior and the P-E fit theory with recent research findings. The resulting conceptual model is depicted in Fig. 1.

\section{Antecedents of Bidirectional Boundary Management Behavior: the Role of Availability Expectations}

Following calls for a better theoretical foundation of research on the work-nonwork interface (Matthews et al., 2016; Wayne et al., 2020), we draw on the theory of planned behavior (Ajzen, 1991; Fishbein \& Ajzen, 2010) to theoretically delineate different categories of predictors of boundary management behavior. According to the theory, three primary factors influence individuals' behavioral intention, which in turn predicts their actual behavior: the individuals' attitude towards the behavior, subjective norms to (not) perform the behavior, and their perceived control over the behavior (Ajzen, 1991; Fishbein \& Ajzen, 2010). Transferred to the context of boundary management, empirical studies underline that boundary management behavior is indeed predicted by individuals' attitude towards the behavior as reflected in boundary management preferences (e.g., Methot \& LePine, 2016; Powell \& Greenhaus, 2010; Palm et al., 2020). Further, indicators of perceived behavioral control such as boundary control, job autonomy, or boundary flexibility-ability were shown to be related to boundary management behavior (e.g., Kossek et al., 2012; Matthews et al., 2010; Palm et al., 2020; Park \& Jex, 2011). Regarding subjective norms, research indicates that due to the increasing dissemination of ICTs employees face rising expectations to be available and responsive to work issues anytime and anywhere (Derks et al., 2015; Mazmanian et al., 2013). In line with the theory of planned behavior, these expectations put employees under pressure to show the desired behavior, thus prompting them to integrate work into nonwork domains by increasing work-related ICT use after hours (e.g., Fenner \& Renn, 2010; Piszczek, 2017). While these prior studies stress the need to take into account norms regarding ICT-enabled availability, they only consider the role of organizational availability expectations, disregarding that availability expectations may differ considerably between organizational members. Specifically, results of a qualitative study by Mazmanian (2013) suggest that employees may perceive distinct expectations from supervisors and coworkers. In addition, although mostly omitted in prior research, availability expectations from nonwork contacts have increased significantly (Matusik \& Mickel, 2011), demanding employees to be available via ICTs when they work. To illuminate whether expectations from those different social groups have distinct relationships with individuals' boundary management behavior, we go beyond prior research and differentiate between supervisor, coworker, and nonwork contact availability expectations. We define supervisor/coworker (nonwork contact) availability expectations as the degree to which employees perceive their supervisors/coworkers (nonwork contacts) demand availability via ICTs in nonwork (work) domains. Using the theory of planned behavior as an organizing framework, 
we not only investigate their effects on individuals' boundary management behavior, but control for individuals' attitude towards boundary management behavior as reflected in boundary management preferences, as well as for perceived control over boundary management behavior as reflected in job autonomy.

We now develop our hypotheses regarding the relationship of the three social groups' availability expectations with segmentation behavior. Research suggests that supervisors' expectations in general play a key role in influencing employees' behavior (Carmeli \& Schaubroeck, 2007). Employees may discern supervisor availability expectations either from supervisors' explicit statements or by observing the supervisors' own work-nonwork availability, interpreting that as representations of what supervisors expect from others (Fishbein and Ajzen 2010). To show aspirations for performing effectively, employees feel pressure to fulfill their supervisors' expectations. Thus, when employees perceive that their supervisors expect high availability, they should show the expected work-nonwork availability behavior (Derks et al., 2015; Mazmanian, 2013). Responding to supervisor availability expectations with higher worknonwork availability, employees increase integration of work into nonwork domains, thereby engaging in the behavior that they perceive their supervisor would approve. Accordingly, we argue that supervisor availability expectations should predict higher work-nonwork integration, i.e., lower worknonwork segmentation.

Hypothesis 1a: Supervisor availability expectations are negatively related to work-nonwork segmentation.

Similarly, coworkers might expect each other to be available beyond working times. Employees may note the availability patterns of their coworkers (Mazmanian, 2013; Mazmanian et al., 2013), or coworkers may explicitly state the extent of work-nonwork availability expected of other team members. In line with the theory of planned behavior, employees should feel social pressure to fulfill their coworkers' availability expectations by aligning their behavior, in order to prove their team commitment or to avoid impeding the communication flow and productivity in their team (Mazmanian et al., 2013). Therefore, individuals who perceive their coworkers as holding high work-nonwork availability expectations should comply with these expectations and increase their work-nonwork availability. Hence, coworker availability expectations should be negatively associated with the extent to which individuals segment work from nonwork domains, beyond supervisor availability expectations.

Hypothesis 1b: Coworker availability expectations are negatively related to work-nonwork segmentation.
In addition, availability expectations from nonwork contacts may put employees under social pressure to be available via ICTs when they work. As individuals are fundamentally motivated to maintain positive relationships with relevant others, they should engage in behaviors aimed at satisfying this motivation (Baumeister \& Leary, 1995). Building on this notion, we argue that individuals should be motivated to avoid violating availability expectations of family members and friends and instead show behaviors that they perceive their nonwork contacts would approve. Accordingly, when individuals are confronted with nonwork contact availability expectations, they should engage in higher availability for nonwork contacts in the work domain. In turn, this should be associated with reduced segmentation of nonwork domains from work.

Hypothesis 1c: Nonwork contact availability expectations are negatively related to nonwork-work segmentation.

\section{The Relationship Between Bidirectional Boundary Management Behavior and Employee Well-Being}

As boundary management behavior is a bidirectional phenomenon that concerns the work domain, nonwork domains, and their interrelations, we propose that it is linked to broad, domain-spanning outcomes as reflected by individual wellbeing. In the present study, we investigate the relationship of boundary management behavior with three indicators of individual well-being: work-nonwork balance, exhaustion, and life satisfaction. In particular, we consider work-nonwork balance as a proximal outcome of individuals' boundary management behavior because it reflects their overall evaluation of how they manage their engagement in multiple life domains (Casper et al., 2018). Work-nonwork balance, in turn, should predict exhaustion and life satisfaction, which represent more general indicators of individual wellbeing that do not directly refer to the work-nonwork interface. Thus, they are proposed to be more distal outcomes of individuals' boundary management behavior.

Prior research investigating consequences of boundary management behavior for work-nonwork balance has largely focused on work-nonwork conflict or work-nonwork enrichment (e.g., Derks et al., 2015; Kubicek \& Tement, 2016), i. e., constructs that reflect how the work domain influences experiences in nonwork domains and vice versa (Casper et al., 2018; Greenhaus \& Allen, 2011). Yet, as recent literature on work-nonwork balance stresses, the balance concept is distinct from enrichment or conflict between work and nonwork domains (Wayne et al., 2017). Instead, balance represents a nondirectional evaluation of how individuals manage their engagement in work and nonwork domains 
simultaneously (Casper et al., 2018). Moreover, individuals hold multiple identities in domains besides work (e.g., family, friends, hobbies) "that vary in salience between people and within the same person over time" (Casper et al., 2018, p. 197). Accordingly, balance should be conceptualized as a broad construct that factors in all domains individuals consider as a relevant part of their life and, thus, all identities that are salient when evaluating work-nonwork balance (Casper et al., 2018; Greenhaus \& Allen, 2011). To underline that we apply such a holistic conceptualization of balance, we use the term life balance instead of work-nonwork balance for the construct we study.

Another aspect that is key to a contemporary conceptualization of balance is the subjectivity of balance perceptions, which emphasizes that individuals may evaluate distinct as well as unequal involvements in different life domains as balance (Greenhaus \& Allen, 2011). This subjectivity is rooted in P-E fit theory (Edwards et al., 1998; Edwards \& Rothbard, 1999), which posits that the person and the environment interact with one another, with a congruence between the person's needs and the environment's supplies resulting in positive outcomes. Thus, from a P-E fit perspective, perceptions of balance should reflect individuals' assessment of the extent to which their involvement in salient life domains is in congruence with their personal needs, as reflected in their aspirations, priorities, or values (Casper et al., 2018; Greenhaus \& Allen, 2011; Maertz \& Boyar, 2011). Accordingly, we define life balance as individuals' global perceptions of alignment between their actual involvement in all life domains of personal relevance, and their personal needs.

We now turn to the relationship of boundary management behavior with life balance. Most prior research on the relationship between boundary management behavior and constructs related to work-nonwork balance points to beneficial effects of segmentation. Work-nonwork segmentation was found to be associated with reduced work-nonwork conflict (Carlson et al., 2015; Kubicek \& Tement, 2016; Matthews et al., 2010), while (ICT-enabled) integration of work into nonwork domains was found to increase work-nonwork conflict (e.g., Bogaerts et al., 2018; Gadeyne et al., 2018). Similarly, the few studies investigating nonwork-work segmentation found that it is related to reduced nonwork-work conflict (Hecht \& Allen, 2009; Matthews et al., 2010). These results indicate that segmentation helps employees reduce negative interferences of one domain in another.

Going beyond these previous studies that link boundary management behavior to outcomes directly related to the work-nonwork interface, we propose that boundary management behavior also affects individuals' more global, nondirectional evaluation of how they manage their engagement in salient life domains, i.e., their life balance. A pioneering study that investigates the effect of actual boundary management behavior on broad, domain-spanning outcomes provides initial support that integration of work into nonwork domains is negatively related to balance perceptions (Wepfer et al., 2018). Validating and extending these findings, we suggest that both work-nonwork and nonwork-work segmentation behaviors are relevant predictors of life balance. In particular, in line with the beneficial effects of segmentation found in prior research, we propose that employees who segment work from nonwork or nonwork from work domains, respectively, should have better preconditions to achieve higher life balance. Segmenting work from nonwork and vice versa helps employees to better focus on the domain they are currently engaged in, without being distracted or disturbed from another (Ashforth et al., 2000). Thereby, they should more likely be able to involve themselves in each domain as they wish to, which should result in better alignment of actual involvement with their personal needs across all relevant life domains.

Hypothesis 2a: Work-nonwork segmentation is positively related to life balance.

Hypothesis 2b: Nonwork-work segmentation is positively related to life balance.

Life balance, as a proximal outcome of boundary management behavior, in turn, should be a critical antecedent of more global, domain-spanning indicators of individual wellbeing (Maertz \& Boyar, 2011; Wayne et al., 2017). Or, as Greenhaus and Allen (2011, p. 179) state, "feelings of workfamily balance enhance, and are an indicator of, psychological health and well-being." Accordingly, as we expound in the following, we propose that life balance precedes more general indicators of individual well-being.

To capture important positive and negative indicators of general well-being, we examine life satisfaction and exhaustion. Perceptions of life balance are the result of a comparison between individuals' actual involvement in relevant life domains with person-specific needs. In line with P-E fit theory, if this appraisal process results in perceived misfit, i.e., when employees feel that their personal needs are insufficiently fulfilled by their actual experiences in salient life domains, persistent states of tension and dissatisfaction are triggered (Edwards \& Rothbard, 1999; Edwards et al., 1998). This sustained negative affect should impair employee well-being as indicated by increased levels of exhaustion and reduced life satisfaction (Edwards \& Rothbard, 1999; Edwards et al., 1998; Lazarus \& Folkman, 1984). Conversely, perceiving an overall congruence between involvement in salient life domains and personal needs, i.e., high life balance, implies that personal standards are being fulfilled. As P-E fit theory suggests, this perceived fit should produce enhanced levels of well-being (Edwards \& Rothbard, 1999; Edwards et al., 1998), reflected in lower 
exhaustion and higher life satisfaction. Accordingly, employees perceiving their life as more balanced should experience less exhaustion and higher overall satisfaction with their life.

Hypothesis 3a: Life balance is negatively related to exhaustion.

Hypothesis $3 b$ : Life balance is positively related to life satisfaction.

\section{Moderating Effects of Boundary Management Preferences}

As individuals differ in their segmentation/integration preferences, the strength of the link between boundary management behavior and life balance may vary, contingent on these preferences (Ashforth et al., 2000; Kreiner, 2006). The P-E fit perspective on the work-nonwork interface (Edwards \& Rothbard, 1999; Kreiner, 2006) provides a valuable theoretical lens to explain this proposition, suggesting that higher degrees of segmentation may not inherently be more beneficial for every individual. Instead, Kreiner (2006) proposes that a fit between individuals' boundary management preferences and the workplace's supply of these preferences predicts higher well-being. Several studies have followed this fit perspective, examining the congruence between individual boundary management preferences and boundary management supplies by the organization, and its effect on wellbeing (e.g., Basile \& Beauregard, 2021; Bogaerts et al., 2018). In the present study, we transfer this fit perspective to a behavioral level, investigating consequences of (mis-) fit between boundary management preferences and actual boundary management behavior.

We argue that the strength of the positive effect of worknonwork and nonwork-work segmentation behavior on life balance should vary, depending on the extent to which the individuals' actual segmentation behavior complies with their segmentation preferences. In particular, we propose that the positive relationship between work-nonwork segmentation and life balance should be stronger for employees with high work-nonwork segmentation preferences, because these employees experience high work-nonwork segmentation as being congruent with their segmentation preferences. This perceived fit between actual boundary management behavior and personal values should reduce stress and conflict (Kreiner, 2006) and therefore enable high levels of life balance. In contrast, when employees with high work-nonwork segmentation preferences engage in low work-nonwork segmentation, they should perceive a mismatch between actual boundary management behavior and personal preferences. In line with P-E fit theory, this mismatch should create a state of tension for these individuals, which should result in low levels of life balance (Edwards et al., 1998; Kreiner, 2006).
The same mechanism should apply to nonwork-work segmentation, such that nonwork-work segmentation behavior should be more strongly related to higher life balance when nonwork-work segmentation preferences are high.

Hypothesis 4a: Work-nonwork segmentation preferences moderate the positive relationship between work-nonwork segmentation and life balance, such that the relationship is stronger when work-nonwork segmentation preferences are higher.

Hypothesis 4b: Nonwork-work segmentation preferences moderate the positive relationship between nonwork-work segmentation and life balance, such that the relationship is stronger when nonwork-work segmentation preferences are higher.

\section{Method}

\section{Sample and Procedure}

To test our hypotheses, we sampled knowledge workers from four companies based in Germany, representing the following industries: IT, automotive supply, consulting, and public administration. We selected knowledge workers, that is, employees who are primarily involved with the "creation, distribution, or application of knowledge" (Davenport, 2005: 11), as ICT-enabled availability is typically of great significance for their work (Wajcman \& Rose, 2011). Potential participants were informed about the study by their employer via email, the company's intranet, and during onsite sessions. As an incentive, all participants received an individualized data-based feedback report to improve their well-being. Further, participants could win one out of 11 shopping vouchers with a value of USD 120.

To reduce common method bias (Podsakoff et al., 2012) and to capture the enduring effects of availability expectations, we collected data in two waves six weeks apart via online surveys. The first survey assessed availability expectations, boundary management preferences, and control variables, whereas boundary management behavior, life balance, exhaustion, and life satisfaction were assessed in the second survey. The first survey $\left(\mathrm{t}_{1}\right)$ was completed by 589 employees who were subsequently contacted six weeks later $\left(t_{2}\right)$. Of those, $68.1 \%$ completed the second survey, resulting in a final sample of 401 participants. In the final sample, 69.3\% are male, $88.5 \%$ are married or in a relationship, and $60.5 \%$ have at least one child who lives with them. The mean age is 45.64 years $(S D=9.04)$. On average, participants have been working in their company for 16.14 years $(S D=9.27)$, and in various departments, including IT (30.2\%), sales and key account management (19.2\%), research and development $(10.7 \%)$, operations and production $(8.2 \%)$, human resources 
(4.5\%), and others (27.2\%). Finally, $18.4 \%$ are managers, $32.7 \%$ are project or team leaders without formal managerial responsibilities, and $48.9 \%$ are employees without managerial responsibilities.

\section{Measures}

Availability Expectations Supervisor availability expectations $(\alpha=0.91)$, coworker availability expectations ( $\alpha=0.90)$, and nonwork contact availability expectations $(\alpha=0.92)$ were measured with two self-developed items each on a 7-point Likert scale (1, strongly disagree, to 7, strongly agree). A sample item for supervisor availability expectations is "Usually, my supervisor expects me to respond to incoming calls or messages when I am not at work." The wording of the items was adapted for coworkers and nonwork contacts, respectively. A sample item for nonwork contact availability expectations is "Usually, my personal contacts expect me to respond to incoming calls or messages when I am at work."

Boundary Management Preferences To measure worknonwork segmentation preferences $(\alpha=0.85)$, we used three items from the segmentation preferences scale developed by Kreiner (2006), assessed on a 7-point Likert scale (1, strongly disagree, to 7, strongly agree). One sample item is: "I prefer to keep work life at work." To assess nonworkwork segmentation preferences $(\alpha=0.65)$, we adapted the items' directionality. A sample item is: "I prefer to keep my personal life out of my work".

Boundary Management Behavior To measure boundary management behavior, we followed the approach by Powell and Greenhaus (2010) and adapted items from the segmentation preferences scale (Kreiner, 2006) such that they captured actual behavior. Thereby, to reflect the segmentation/integration continuum, each scale included one item assessing integration. Work-nonwork segmentation behavior $(\alpha=0.84)$ and nonwork-work segmentation behavior $(\alpha=0.82)$ were measured by three items each on a 7-point Likert scale (1, strongly disagree, to 7, strongly agree). Participants were asked to indicate the extent to which they agreed with each item with regard to the past six weeks, that is, the period since the first survey. One sample item for work-nonwork segmentation behavior is: "I left work behind when I went home." To measure nonwork-work segmentation behavior, we modified the items' directionality. A sample item is: "I left my personal life behind when I went to work." A sample item reflecting nonwork-work integration is: "I took care of personal matters when I was at work," which was reversed for analyses.
Life Balance Life balance was assessed with a scale developed by the authors, since no validated measure of worknonwork balance was available at that time that reflected the conceptualization of life balance we employ. That is, available measures of balance either did not capture perceived fit between individual's domain involvement and personal needs or did not incorporate all life domains the individual considers as salient. Accordingly, we developed four items to assess individuals' global perceptions of the congruence between their actual involvement in all life domains of personal relevance and their personal needs, i.e., life balance: "Overall, I was able to live my life in all domains just as I wished," "On the whole, I feel that I was the person I wished to be in all domains of my life," "On balance, how I involved myself in the domains of my life matches my ideal image," and "Overall, I am convinced that I shaped all domains of my life as I ideally would want them to be."

To validate the measure, we conducted an additional validation study prior to the start of our two-wave study with 83 participants who were recruited via diverse social media platforms (mean age: 35 years; $50.6 \%$ male; $68.7 \%$ married or in a relationship). All participants were professionals, either employed full-time (56.6\%), part-time (15.7\%), selfemployed $(18.1 \%)$, or others $(9.6 \%$, e.g., working student). Results of confirmatory factor analysis (CFA) with Mplus 8.5 (Muthén \& Muthén, 1998-2017) suggested adequate fit for the one-factor model $\left(\chi^{2}=3.71, d f=2 ; R M S E A=0.10\right.$; $C F I=0.99, S R M R=0.01)$. Further, we tested the scale's discriminant validity in its nomological net, including satisfaction with work-life balance ( $\alpha=0.93$; Valcour, 2007) as well as work-life conflict $(\alpha=0.93)$, and life-work conflict ( $\alpha=0.91$; Netemeyer et al., 1996). Results for life balance and satisfaction with work-life balance suggested that a twofactor model $\left(\chi^{2}=56.07, d f=26 ; R M S E A=0.12 ; C F I=0.95\right.$, $S R M R=0.04)$ fits the data significantly better than a one-factor model $\left(\chi^{2}=356.10, d f=27 ; R M S E A=0.38 ; C F I=0.49\right.$, $S R M R=0.26)$. The inter-factor correlation between life balance and satisfaction with work-life balance was medium with $r=0.34$. We found similar results regarding work-life conflict, with the two-factor model $\left(\chi^{2}=29.68, d f=26\right.$; $R M S E A=0.04 ; C F I=0.99, S R M R=0.04)$ fitting the data better than the one-factor model $\left(\chi^{2}=323.93, d f=27\right.$; $R M S E A=0.36 ; C F I=0.54, S R M R=0.22)$, as well as with life-work conflict (two-factor model: $\chi^{2}=34.01, d f=26$; $R M S E A=0.06 ; C F I=0.99, S R M R=0.05$; one-factor model: $\chi^{2}=276.46, d f=27 ; R M S E A=0.33 ; C F I=0.57$, $S R M R=0.23)$. Again, inter-factor correlations between life balance and work-life conflict $(r=-0.45)$ as well as lifework conflict $(r=-0.35)$ were medium of size. For our main study, participants were asked to indicate the extent to which they agreed with each item with regard to the past 6 weeks on a 7-point Likert scale (1, strongly disagree, to 7, 
strongly agree). Cronbach's alpha score for the scale in this sample was $\alpha=0.96$.

Exhaustion Exhaustion $(\alpha=0.91)$ was measured using the five-item scale for exhaustion from the Maslach Burnout Inventory General Survey (Maslach et al., 1996), assessed on a 7-point scale (1, never, to 7, daily). A sample item is: "I feel burned out from my work."

Life Satisfaction We assessed life satisfaction $(\alpha=0.90)$ with five items using the satisfaction with life scale (Pavot $\&$ Diener, 1993). Participants were asked to rate the extent to which they agreed with each item on a 7-point Likert scale ( 1 , strongly disagree, to 7 , strongly agree $)$. A sample item is: "I am satisfied with my life."

Control Variables In addition to controlling for job autonomy as an indicator for perceived behavioral control, we included job involvement, personal life involvement, and job demands as control variables in our model, as these are likewise considered important predictors of boundary management behavior and well-being (Boswell \& OlsonBuchanan, 2007; Demerouti et al., 2001; Frone et al., 1992). Job autonomy ( $\alpha=0.73$ ) describes the extent to which a job allows for individual freedom in decision-making and completing work tasks and was assessed by three items from the autonomy scale of the Work Design Questionnaire (Morgeson \& Humphrey, 2006). Job and personal life involvement represent the degree to which an individual's job and personal life, respectively, are central to their self-concept (Kanungo, 1982). Job involvement $(\alpha=0.76)$ and personal life involvement $(\alpha=0.87)$ were measured with four items each adapted from Frone and Rice (1987). Job demands $(\alpha=0.83$ ) represent job characteristics that are perceived as sources of stress and were measured with four items from Richter et al. (2000). All items were assessed on a 7-point Likert scale (1, strongly disagree, to 7, strongly agree). In addition, we controlled for the participants' organizational membership by creating three dummy variables.

\section{Results}

Table 1 shows the means, standard deviations, and correlations among our variables. We tested our hypotheses using structural equation modeling (SEM) with Mplus 8.5.

\section{Measurement Model Testing}

We first tested our measurement model to assess the construct validity of the ten latent study variables and four latent control variables, using the maximum likelihood estimator with robust standard errors (MLR).
Results suggest that the proposed measurement model fits the data well $\left(\chi^{2}(943)=1729.14, p<0.001\right.$; $R M S E A=0.046 ; C F I=0.93, S R M R=0.055)$, with each item loading significantly on the respective latent variable $(p<0.001)$.

Next, we tested alternative nested models with fewer factors and compared them to our proposed measurement model via Satorra-Bentler scaled chi-square difference tests. As our proposed measurement model showed high correlations between life balance and life satisfaction $(r=0.698)$, as well as between life balance and exhaustion $(r=-0.674)$, we started with testing two alternative models in which the two respective constructs were set to load onto one factor. Results suggested worse model fit for the model with life balance and life satisfaction loading onto one factor, with $\chi^{2}(956)=2482.06, p<0.001 ; R M S E A=0.063 ; C F I=0.86$, $S R M R=0.065 ; \Delta \chi^{2}(13)=609.95, p<0.001$. Similarly, the model with life balance and exhaustion (reversed-coded) loading onto one factor likewise showed worse fit, with $\chi^{2}(956)=2491.83, p<0.001 ; R M S E A=0.063 ; C F I=0.86$, $S R M R=0.061 ; \Delta \chi^{2}(13)=678.31, p<0.001$. In addition, we tested a ten-factor model in which the three availability expectation measures for supervisors, coworkers, and nonwork contacts, as well as the work-nonwork and nonwork-work segmentation preferences items, and the items for work-nonwork and nonwork-work segmentation behavior, were set to load onto one factor, respectively. This model likewise showed worse fit $\left(\chi^{2}(989)=3186.60\right.$, $p<0.001 ; R M S E A=0.074 ; C F I=0.80, S R M R=0.086$; $\left.\Delta \chi^{2}(46)=1172.61, p<0.001\right)$. Finally, a model in which the items for supervisor and coworker availability expectations were set to load onto one factor, suggested worse model fit $\left(\chi^{2}(956)=2045.20, p<0.001 ; R M S E A=0.053\right.$; $C F I=0.90, S R M R=0.058 ; \Delta \chi^{2}(13)=232.73, p<0.001$ ). Thus, the results suggest that our study variables measure distinct constructs and we continued with our proposed measurement model.

\section{Hypotheses Testing}

To test our main effect hypotheses (Hypotheses 1-3), we specified the proposed paths between our latent study variables. Hereby, we controlled for paths from all control variables to all endogenous variables as well as from boundary management preferences to boundary management behavior. Standardized paths for the model (Model 1) are shown in Tables 2 and 3. Exogenous latent variables were allowed to covary, as well as exhaustion and life satisfaction. Those additional effects are shown in Table 4 . Results indicate good model fit $\left(\chi^{2}(1095)=2104.98\right.$, $p<0.001 ; R M S E A=0.048 ; C F I=0.91 ; S R M R=0.066)$. Hence, we continued with examining our research hypotheses. 


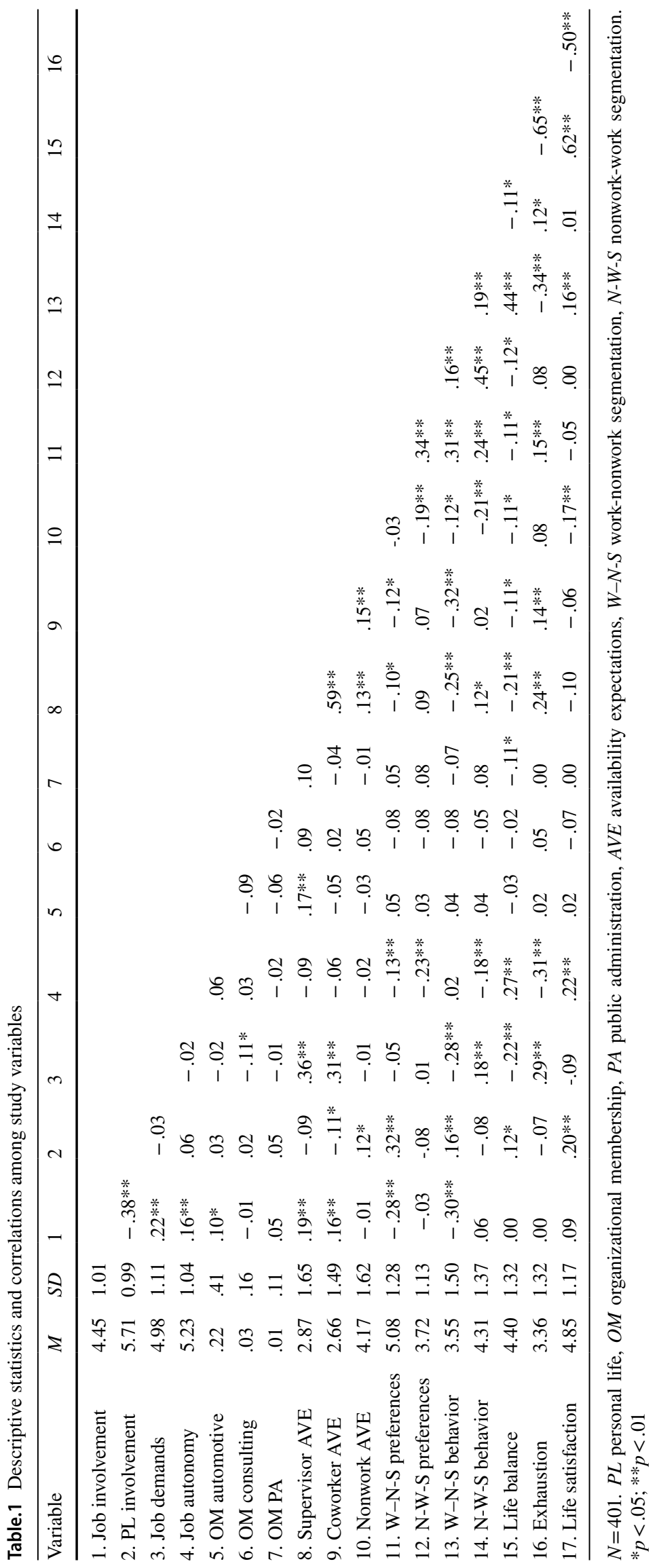


As regards predictors of boundary management behavior, the relationship between supervisor availability expectations and work-nonwork segmentation behavior was not significant $(\beta=0.05, p=0.51)$. Yet, coworker availability expectations were negatively related to work-nonwork segmentation behavior $(\beta=-0.21, p<0.01)$, beyond the positive effect of work-nonwork segmentation preferences $(\beta=0.26, p<0.001)$. In addition, nonwork contact availability expectations negatively predicted nonwork-work segmentation behavior $(\beta=-0.14, p<0.05)$, beyond the positive effect of nonwork-work segmentation preferences ( $\beta=0.46, p<0.001)$. Thus, the results supported Hypotheses $1 \mathrm{~b}$ and $1 \mathrm{c}$, but not Hypothesis 1a. Regarding effects on life balance, work-nonwork segmentation behavior was positively related to life balance $(\beta=0.49, p<0.001)$. Contrary to expectations, nonwork-work segmentation behavior was negatively associated with life balance $(\beta=-0.11, p<0.05)$. Accordingly, the results supported Hypothesis $2 \mathrm{a}$, but not Hypothesis $2 \mathrm{~b}$. Finally, life balance was negatively related to exhaustion $(\beta=-0.56, p<0.001)$, and positively related to life satisfaction $(\beta=0.68, p<0.001)$, providing support for Hypotheses $3 \mathrm{a}$ and $3 \mathrm{~b}$. Together, $29.6 \%$ of the variance in work-nonwork segmentation behavior and $31.6 \%$ of the variance in nonwork-work segmentation behavior were explained. Further, the model explained $41.7 \%$ of the variance in life balance, $55.6 \%$ of the variance in exhaustion, and $54.9 \%$ of the variance in life satisfaction.

Next, to test the hypothesized moderation effects (Hypothesis 4), we estimated a moderation model (Model 2 ) in which the latent interactions terms of work-nonwork segmentation preferences and work-nonwork segmentation behavior, as well as of nonwork-work segmentation preferences and behavior, and their effects were added to Model 1. We followed the latent moderated structural equations (LMS) approach (Klein \& Moosbrugger, 2000) and used the XWITH command in Mplus to estimate the latent interaction terms (Cheung et al., 2021). Due to biases to the chi-square value, reporting conventional model fit indices is not possible when nonlinear latent interaction terms are added to the model. Therefore, we compared the linear SEM model without moderating effects (Model 1) to the SEM model including the moderation effects (Model 2) by using a chisquare difference test based on log-likelihood values and scaling correction factors from MLR (Cheung et al., 2021; Klein \& Moosbrugger, 2000). Tables 2 and 3 show the results for the moderation model. ${ }^{1}$ In support of Hypothesis $4 \mathrm{a}$, results revealed that work-nonwork segmentation preferences significantly moderated the positive relationship

\footnotetext{
${ }^{1}$ It should be noted that in Model 2, the negative effect of nonworkwork segmentation on life balance became nonsignificant. All other proposed main effects did not change. We discuss this finding in the implications section.
}

between work-nonwork segmentation behavior and life balance $(\beta=0.12, p<0.01)$. Contrary to Hypothesis $4 \mathrm{~b}$, nonwork-work segmentation preferences did not moderate the relationship between nonwork-work segmentation behavior and life balance $(\beta=-0.03, p=0.66)$. Results of the difference test suggested that Model 2 provided better fit to the data than Model 1 (TRd (5) $=5124.34 ; p<0.001)$. Figure 2 summarizes the results for the hypothesized relationships for Models 1 and 2.

To further inspect the interaction effect of work-nonwork segmentation preferences and work-nonwork segmentation behavior, we conducted simple-slope tests using the MODEL CONSTRAINT option in Mplus (Cheung et al., 2021). Results suggested that the positive relationship between work-nonwork segmentation behavior and life balance was stronger for individuals with high work-nonwork segmentation preferences $(B=0.81, p<0.001$ for one standard deviation and $B=0.95, p<0.001$ for two standard deviations above the mean) than for individuals with low work-nonwork segmentation preferences $(B=0.54, p<0.001$ for one standard deviation and $B=0.40, p<0.01$ for two standard deviations below the mean). We depict the interaction effect in Fig. 3.

\section{Supplemental Analyses}

To further explore the relationship of availability expectations as well as boundary management behavior with individual well-being, we examined the significance of their indirect effects, which can be obtained from the MODEL INDIRECT function applied on Model 1, and inspected the corresponding 95\% confidence intervals (CI). Regarding availability expectations, results showed significant indirect effects of coworker availability expectations on life balance through work-nonwork segmentation behavior (estimate $=-0.10, p<0.01 ; 95 \% \mathrm{CI}=-0.17 ;-0.04)$, as well as on exhaustion (estimate $=0.06, p<0.01 ; 95 \% \mathrm{CI}=0.02$; 0.10 ) and life satisfaction (estimate $=-0.07, p<0.01$; $95 \% \mathrm{CI}=-0.12 ;-0.03)$ through work-nonwork segmentation behavior and life balance. Supervisor and nonwork contact availability expectations did not exhibit any indirect effects. However, since supervisors are likely to influence their team availability culture (Mazmanian, 2013), we further tested whether supervisor expectations indirectly predicted employees' boundary management behavior and well-being via coworkers' availability expectations in an additional model. Results showed a negative indirect effect of supervisor availability expectations on life balance via coworker availability expectations and work-nonwork segmentation behavior (estimate $=-0.07, p<0.01$; 95\% $\mathrm{CI}=-0.12 ;-0.03$ ). Further, supervisor expectations indirectly predicted exhaustion (estimate $=0.04, p<0.01 ; 95 \%$ $\mathrm{CI}=0.02 ; 0.07$ ) and life satisfaction (estimate $=-0.05$, 


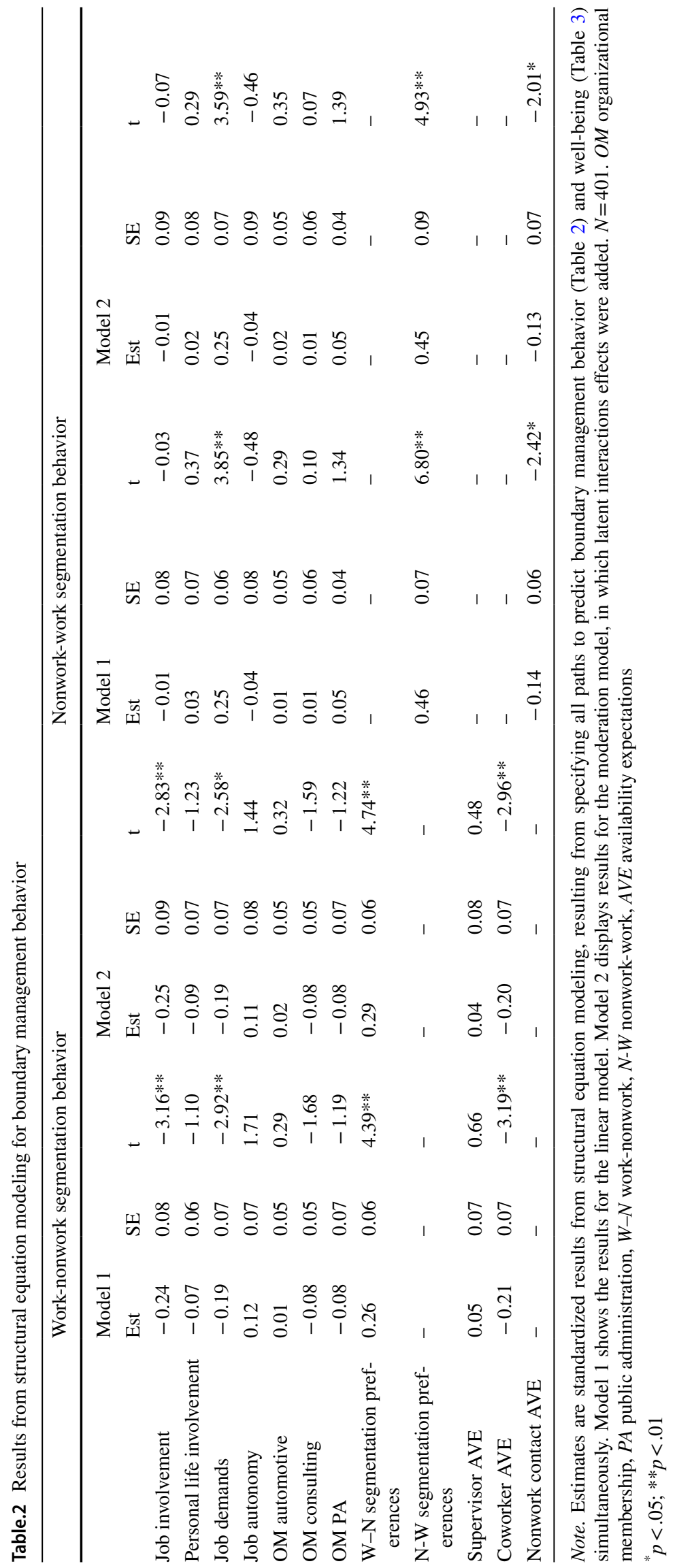




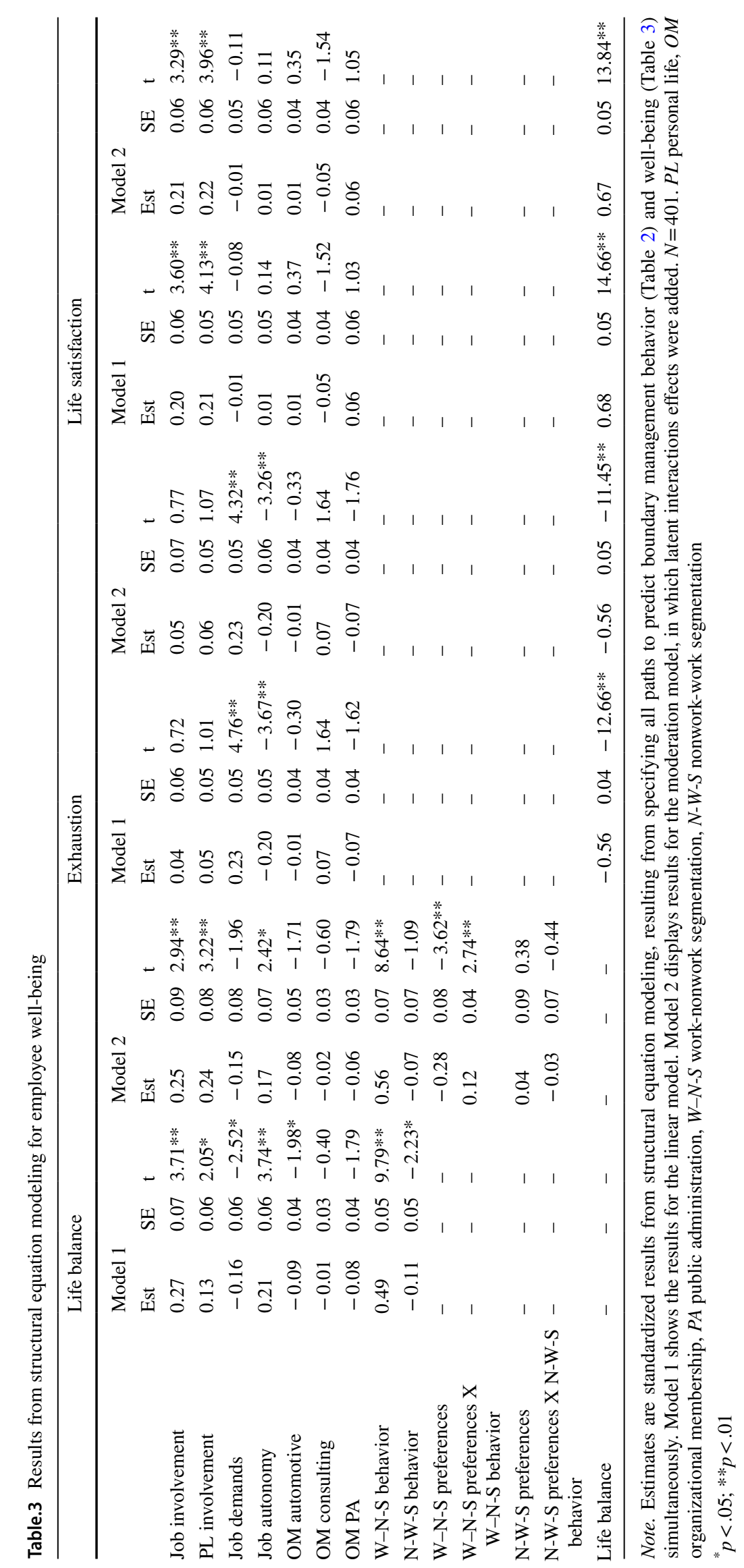


Table.4 Additional effects accounted for in our structural equation modeling

\begin{tabular}{|c|c|c|c|c|c|c|c|c|c|c|}
\hline & 1 & 2 & 3 & 4 & 5 & 6 & 7 & 8 & 9 & 10 \\
\hline 1. Job involvement & - & & & & & & & & & \\
\hline 2. Personal life involvement & $\begin{array}{l}-0.47 * * \\
(-0.47 * *)\end{array}$ & - & & & & & & & & \\
\hline 3. Job demands & $\begin{array}{l}0.29^{* *} \\
(0.29 * *)\end{array}$ & $\begin{array}{l}-0.05 \\
(-0.05)\end{array}$ & - & & & & & & & \\
\hline 4. Job autonomy & $0.22 * *(0.22 * *)$ & $\begin{array}{l}0.08 \\
(0.08)\end{array}$ & $\begin{array}{l}-0.06 \\
(-0.06)\end{array}$ & - & & & & & & \\
\hline 5. $\mathrm{W}-\mathrm{N}-\mathrm{S}$ preferences & $\begin{array}{l}-0.36^{* *} \\
\left(-0.36^{* *}\right)\end{array}$ & $\begin{array}{l}0.37 * * \\
(0.37 * *)\end{array}$ & $\begin{array}{l}-0.05 \\
(-0.04)\end{array}$ & $\begin{array}{l}-0.17 * * \\
(-0.19 * *)\end{array}$ & - & & & & & \\
\hline 6. N-W-S preferences & $\begin{array}{l}-0.02 \\
(-0.02)\end{array}$ & $\begin{array}{l}-0.14 \\
\left(-0.14^{*}\right)\end{array}$ & $\begin{array}{l}-0.04 \\
(-0.04)\end{array}$ & $\begin{array}{l}-0.33 * * \\
(-0.34)^{* *}\end{array}$ & $\begin{array}{l}0.34 * * \\
(0.34 * *)\end{array}$ & - & & & & \\
\hline 7. Supervisor AVE & $0.24 * *(0.24 * *)$ & $\begin{array}{l}-0.11 \\
(-0.11)\end{array}$ & $\begin{array}{l}0.39 * * \\
\left(0.39^{* *}\right)\end{array}$ & $\begin{array}{l}-0.13 \\
(-0.12)\end{array}$ & $\begin{array}{l}-0.10 \\
(-0.10)\end{array}$ & $\begin{array}{l}0.14^{*} \\
\left(0.14^{*}\right)\end{array}$ & - & & & \\
\hline 8. Coworker AVE & $\begin{array}{l}0.21 * * \\
(0.21 * *)\end{array}$ & $\begin{array}{l}-0.13^{*} \\
\left(-0.14^{*}\right)\end{array}$ & $\begin{array}{l}0.34 * * \\
(0.34 * *)\end{array}$ & $\begin{array}{l}-0.07 \\
(-0.07)\end{array}$ & $\begin{array}{l}-0.15^{*} \\
\left(-0.14^{*}\right)\end{array}$ & $\begin{array}{l}0.10 \\
(0.10)\end{array}$ & $\begin{array}{l}0.64^{* *} \\
(0.64 * *)\end{array}$ & - & & \\
\hline 9. Nonwork contact AVE & $\begin{array}{l}-0.02 \\
(-0.02)\end{array}$ & $\begin{array}{l}0.12 \\
(0.12 *)\end{array}$ & $\begin{array}{l}0.01 \\
(-0.01)\end{array}$ & $\begin{array}{l}-0.04 \\
(-0.03)\end{array}$ & $\begin{array}{l}-0.03 \\
(-0.03)\end{array}$ & $\begin{array}{l}-0.25 * * \\
(-0.22 * *)\end{array}$ & $\begin{array}{l}0.15^{* *} \\
\left(0.14^{* *}\right)\end{array}$ & $\begin{array}{l}0.17^{* *} \\
\left(0.16^{* *}\right)\end{array}$ & - & - \\
\hline 10. Exhaustion & - & - & - & - & - & - & - & - & - & - \\
\hline 11. Life satisfaction & - & - & - & - & - & - & - & - & - & $\begin{array}{l}-0.14 * \\
\left(-0.14^{*}\right)\end{array}$ \\
\hline
\end{tabular}

Note. Estimates are standardized correlation estimates from structural equation modeling for Model 2, resulting from setting all exogenous latent variables free to correlate (variables 1-9), as well as exhaustion and life satisfaction, when specifying paths to predict boundary management behavior and well-being simultaneously. Estimates in parentheses are standardized correlation estimates from structural equation modeling for Model 1. $N=401 . W-N-S$ work-nonwork segmentation, $N-W-S$ nonwork-work segmentation, $A V E=$ availability expectations. * $p<.05$; ** $p<.01$

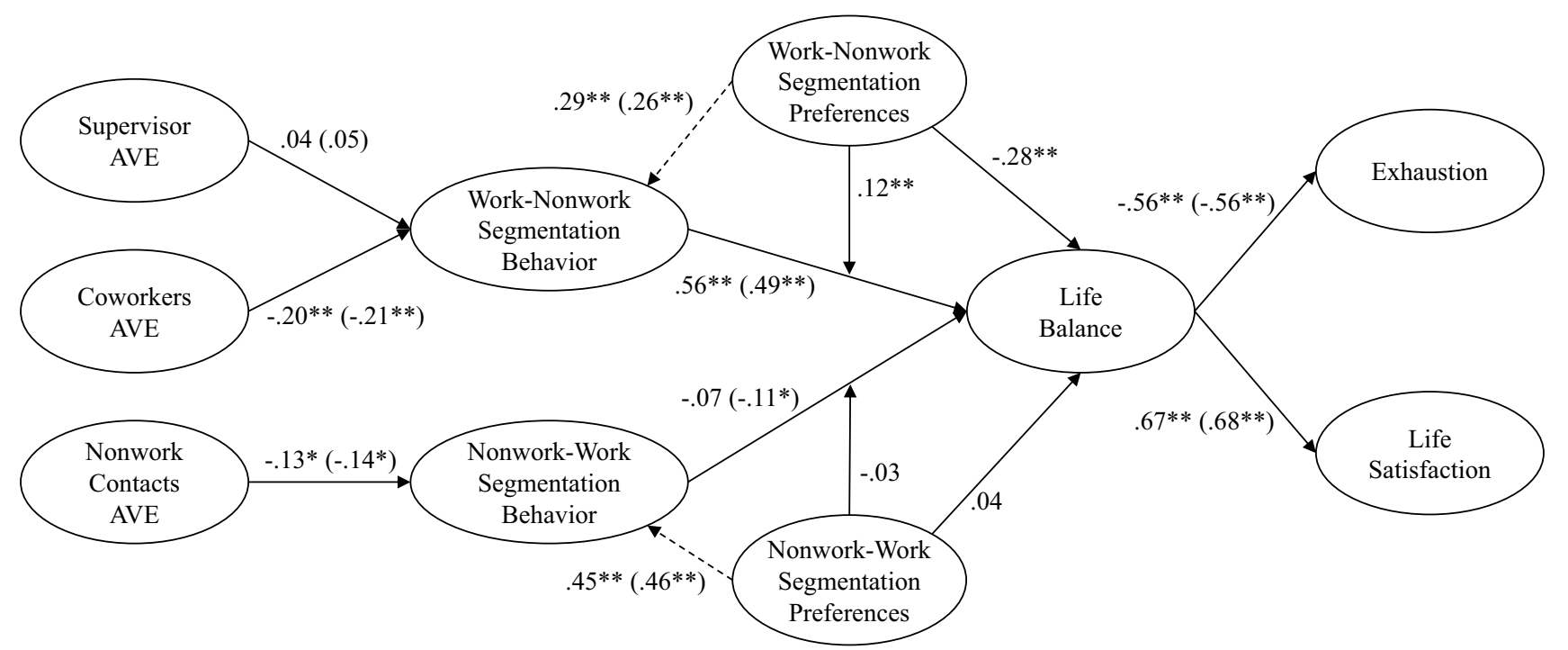

Fig. 2 SEM results with standardized coefficients for the hypothesized relationships from the linear model (Model 1) and the moderation model (Model 2). Coefficients in parentheses are from Model 1. Dashed lines represent effects that were controlled for yet not hypothesized. For reasons of clarity, the paths from the control variables

$p<0.01 ; 95 \% \mathrm{CI}=-0.08 ;-0.02)$ via coworker availability expectations, work-nonwork segmentation behavior, and life balance. job autonomy, job demands, job involvement, personal life involvement, and organizational membership to endogenous variables are not displayed in the model. AVE $=$ availability expectations. $N=401$ $* p<0.05 ; * * p<0.01$

Regarding the indirect effects of boundary management behavior, the results showed that work-nonwork segmentation behavior exhibited a negative indirect 


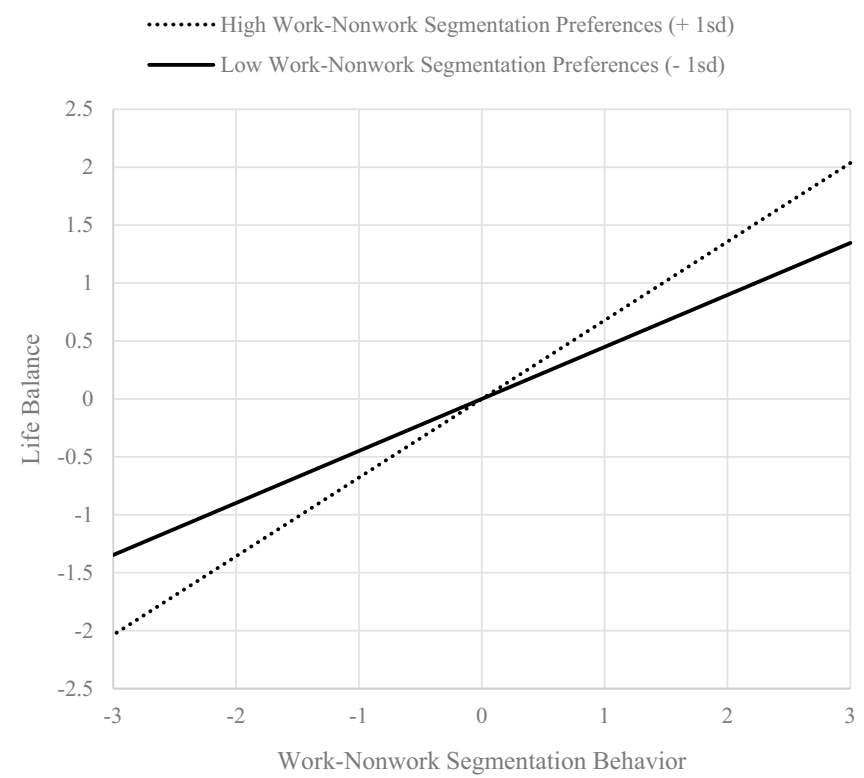

Fig. 3 Work-nonwork segmentation preferences as a moderator of the relationship between work-nonwork segmentation behavior and life balance. Standardized simple slopes are presented for one standard

effect on exhaustion (estimate $=-0.28, p<0.001 ; 95 \%$ $\mathrm{CI}=-0.35 ;-0.20)$ and a positive indirect effect on life satisfaction (estimate $=0.33, p<0.001 ; 95 \% \mathrm{CI}=0.26 ; 0.41$ ) via life balance. Conversely, nonwork-work segmentation behavior showed a positive indirect effect on exhaustion (estimate $=0.06, p<0.05 ; 95 \% \mathrm{CI}=0.01 ; 0.12$ ) and a negative indirect effect on life satisfaction (estimate $=-0.08$, $p<0.05 ; 95 \% \mathrm{CI}=-0.14 ;-0.01)$ via life balance.

\section{Discussion}

This study features a holistic, theory-based approach to boundary management that differentiates work-nonwork and nonwork-work segmentation behavior and integrates antecedents and outcomes of both behaviors, which were often studied in isolation or considered only theoretically. Thereby, we contribute to a more comprehensive understanding of differential drivers and outcomes of boundary management behavior, their relative importance, and conditions. Our results show that perceived availability expectations of coworkers and nonwork contacts have the power to alter how employees manage both work and nonwork boundaries, beyond other well-established antecedents. Further, work-nonwork and nonwork-work segmentation behavior showed divergent effects on individuals' life balance, which in turn was strongly related to exhaustion and life satisfaction. Finally, our study suggests that boundary management preferences play an important role in determining

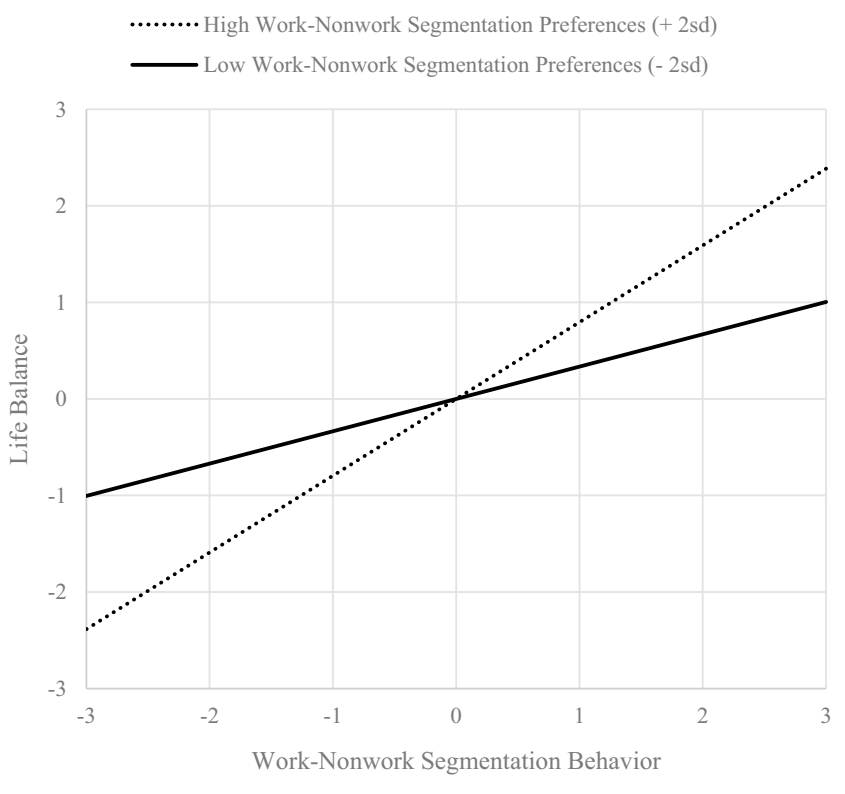

deviation above and below the mean (left plot) and for two standard deviations above and below the mean (right plot)

the strength of the relationship between work-nonwork segmentation behavior and well-being.

\section{Theoretical Implications}

The present study contributes to research on boundary management in the age of ICT-enabled availability in several ways. First, our findings shed light on the role of supervisor, coworker, and nonwork contact availability expectations as drivers of employees' bidirectional boundary management behavior. Simultaneously investigating the effects of the three groups, we find that coworker availability expectations are negatively related to work-nonwork segmentation behavior and even have the power to indirectly predict lower employee well-being through their effect on work-nonwork segmentation behavior. Contrary to our hypothesis, supervisor availability expectations did not exhibit a direct effect on employees' work-nonwork segmentation behavior when coworker availability expectations were accounted for. This unexpected finding might be ascribed to flattened organizational hierarchies and the ever-growing prevalence of teamwork, which is why employees need to interact less frequently and intensively with supervisors than with coworkers to accomplish their tasks (Chiaburu \& Harrison, 2008). Due to the high interdependence among coworkers to carry out their job, employees might feel obligated to participate in and maintain their team's communication flow or to help out a coworker, even after hours (Braukmann et al., 2018; Mazmanian et al., 2013). Hence, it might be more relevant 
for employees to satisfy their coworkers' availability expectations than those of their supervisor, such that coworker but not supervisor availability expectations relate to reduced work-nonwork segmentation behavior. Yet, availability expectations of supervisors as authorities and role models might impact the availability norms that are established among coworkers (Derks et al., 2015; Mazmanian, 2013). Thus, we tested whether supervisors indirectly predicted work-nonwork segmentation behavior via coworker availability expectations in supplemental analyses. The significant indirect path we found substantiates previous findings, proposing that supervisors shape their teams' availability culture and thereby have an indirect impact on subordinates' boundary management behavior and, consequently, on their well-being.

Regarding availability expectations of nonwork contacts, our study shows their incremental, negative effect on nonwork-work segmentation behavior beyond control variables, such that higher expectations lead to a higher integration of nonwork matters into work. Substantiating previous qualitative findings (Matusik \& Mickel, 2011), our results indicate that nonwork contact availability expectations indeed are an important determinant of boundary management behavior. Yet, as they are negatively related to nonwork-work segmentation behavior but not to well-being, nonwork contact availability expectations might not represent a potentially harmful demand for employees - as opposed to coworker availability expectations. Together, our findings point to the importance of differentiating between availability expectations of distinct social groups to gain a holistic picture of how demands accompanying ICT-enabled availability are linked to employees' boundary management behavior.

Second, we address recent calls to study a holistic and theory-based framework of antecedents of boundary management behavior. As recommended by Matthews et al. (2016), we draw on the theory of planned behavior (Ajzen, 1991; Fishbein and Ajzen 2010) to examine availability expectations as a reflection of perceived subjective norms towards segmentation, while accounting for the effects of employees' attitudes toward the behavior as reflected in boundary management preferences, their control over the behavior as reflected in job autonomy, and other well-established antecedents such as job involvement. Thereby, as suggested by Wayne et al. (2020), we simultaneously investigate person, work, and nonwork characteristics as antecedents of boundary management behavior. In doing so, our study extends and integrates previous research (e.g., Matusik \& Mickel, 2011; Palm et al., 2020; Piszczek, 2017), allowing us to draw initial conclusions on the relative importance of the examined antecedents. Our findings suggest that individuals' boundary management preferences, i.e., their personal attitude toward segmenting or integrating work and nonwork domains, represent the strongest predictor of segmentation behavior for both directions. The second strongest predictor of individuals' boundary management behavior were perceived subjective norms from work contacts, in particular coworker availability expectations, followed by perceived subjective norms from nonwork contacts, that is, nonwork availability expectations. Behavioral control as reflected in job autonomy did not show any effects on boundary management behavior in our study. Overall, this pattern substantiates recent findings by Palm et al. (2020), which suggest that both individual preferences and organizational norms substantially impact individuals' work-nonwork integration behavior, while perceived behavioral control does not necessarily "indicate its behavioral realization" (Palm et al., 2020, p. 692). When interpreting our results, it should be noted that we assessed job autonomy as an indicator of perceived behavioral control, suggesting that flexibility in when and how employees work should be relevant for both their work-nonwork and nonwork-work segmentation behavior. Future studies could extend this approach by explicitly differentiating perceived control over both the nonwork and the work boundary.

Third, our study contributes to a differentiated understanding of the relationship of bidirectional boundary management behavior with employee well-being. As previous research has primarily focused on domain-specific outcomes closely related to interferences at the work-nonwork interface (e.g.Carlson et al., 2015; Kubicek \& Tement, 2016), we extend knowledge on the consequences of boundary management behavior, investigating its impact on life balance as a proximal outcome variable and, in turn, life balance's impact on exhaustion and life satisfaction as more distal outcomes. Our results show that boundary management indeed contributes to more global, domain-spanning indicators of well-being. This finding clearly illustrates the relevance of investigating the drivers of boundary management behavior and conditions of its effects to find effective measures for managing boundaries in a healthy and productive way.

Contrary to our expectations, our results suggest that work-nonwork and nonwork-work segmentation behavior have divergent effects on life balance and, consequently, divergent indirect effects on exhaustion and life satisfaction. Specifically, work-nonwork segmentation behavior was positively related to life balance. Yet, contrary to our hypothesis, nonwork-work segmentation behavior had a negative relationship with life balance, which became nonsignificant in the moderation model. This unexpected finding might be explained by the interplay of two opposing mechanisms. On one side, nonwork-work segmentation should reduce interruptions and negative interferences between the two domains. Yet at the same time, it might 
reduce positive spillover from nonwork domains to the work domain (Powell \& Greenhaus, 2010). While this notion should be true for both nonwork-work and worknonwork segmentation behaviors, our results together with prior findings on work-nonwork segmentation suggest that the relative effects of these opposing mechanisms should be contingent on directionality. Previous studies indicate that the benefits of work-nonwork segmentation might outweigh its costs, as work-nonwork segmentation was found to be more strongly related to reduced worknonwork conflict than to reduced positive work-nonwork spillover (Powell \& Greenhaus, 2010) or reduced worknonwork enrichment (Carlson et al., 2015). Our results extend these findings by indicating that for nonwork-work segmentation, the opposite mechanism may apply: The costs of nonwork-work segmentation, such as less transfer of positive affect or support from family and friends to work, may outweigh (or at least be equal with) its benefits, such as reduced interruptions by nonwork contacts during work. Overall, this might result in lower (or unaltered) well-being. Further research is needed to test this proposed interplay of beneficial and detrimental impacts of segmentation behavior on well-being.

The divergent effects of work-nonwork and nonworkwork segmentation behavior have several implications for research. On the one hand, they provide additional evidence that segmenting work form nonwork domains is not only beneficial for reducing work-life conflict (e.g., Carlson et al., 2015; Hecht \& Allen, 2009) but also contributes to global perceptions of balance. On the other hand, our results suggest to divert from the proposition that segmentation is per se beneficial for the individual with regard to nonwork-work segmentation behavior. Instead, our findings indicate that individuals' well-being might benefit from engaging in asymmetric boundary management, i.e., from maintaining a rather clear and thick nonwork boundary to separate work from nonwork domains, while simultaneously increasing the flexibility and permeability of the work boundary to enable inclusion of nonwork matters. This substantiates recent findings by Wayne et al. (2020), indicating asymmetrical processes for work-nonwork and nonwork-work phenomena and their respective effects on well-being.

Fourth, applying notions of P-E fit theory (Edwards \& Rothbard, 1999; Kreiner, 2006), our research contributes to our understanding of the conditions under which a given boundary management behavior is linked to enhanced or impaired well-being. Our results suggest that the strength of the positive relationship between work-nonwork segmentation behavior and life balance varies with individuals' work-nonwork segmentation preferences. Specifically, for individuals with high work-nonwork segmentation preferences, life balance was high when their preferences were fulfilled — that is, when they actually segmented work from nonwork domains - but low when they engaged in low work-nonwork segmentation. For individuals with low worknonwork segmentation preferences, the relationship between work-life segmentation and life balance still remained positive, yet the strength of this relationship was lower. This result implies that for individuals with high work-nonwork segmentation preferences, a (mis-)fit between their preferences and their boundary management behavior might be particularly critical for their well-being. On the other hand, for individuals with low work-nonwork segmentation preferences, engaging in low vs. high work-nonwork segmentation behavior might not lead to such radical changes in their wellbeing. Conversely, our results even suggest that a misfit may result in a slight increase in these individuals' well-being. An explanation for this finding might be that individuals with low work-nonwork segmentation preferences - while liking work-nonwork integration - do not perceive high work-nonwork segmentation as a burden. Hence, despite engaging in high instead of the preferred low work-nonwork segmentation, they may not experience a strong state of tension due to that mismatch but might even benefit, for example, from experiencing less work-life conflict. Contrary to our hypothesis, nonwork-work segmentation preferences did not moderate the relationship between nonwork-work segmentation behavior and life balance. Further, the negative effect of nonwork-work segmentation behavior on life balance became nonsignificant in the moderation model. Together, these results again hint at asymmetrical mechanisms for work-nonwork and nonwork-work phenomena, suggesting that managing the nonwork boundary might be more crucial for individuals' well-being than managing the work boundary - particularly when individuals prefer their nonwork boundary to be clear and thick.

Overall, by drawing on principles of the theory of planned behavior and the P-E fit theory to develop a comprehensive framework of antecedents, outcomes, and conditions of bidirectional boundary management behavior, our study contributes to overcoming the much-criticized paucity of theory application in research on the work-nonwork interface (Matthews et al., 2016; Wayne et al., 2020). Our findings underline the importance to simultaneously examine both directions of boundary management to integrate and validate the rather asymmetric findings on work-nonwork and nonwork-work phenomena (Wayne et al., 2020). Likewise, our holistic study approach and research findings indicate the need for further theory development on the mechanisms around bidirectional boundary management.

\section{Practical Implications}

Our research also brings several practical implications. Together, our findings indicate that organizations should create working conditions that allow employees to segment 
work from nonwork domains to the extent of their preferences, while allowing for integration of nonwork matters into work. Facilitating these boundary management behaviors contributes to employees' well-being, which in turn is linked to job-related outcomes such as performance and turnover intention (Wright \& Huang, 2012).

To support their employees in achieving higher worknonwork segmentation - especially for employees with high work-nonwork segmentation preferences - organizations could utilize two levers. First, they could prevent the development of availability expectations that force employees into unwanted degrees of work-nonwork segmentation. For instance, all employees should be sensitive to the impact their availability expectations have on their coworkers' worknonwork segmentation behavior and, indirectly, even on their well-being. Likewise, managers should be sensitive to their influence on the creation of availability expectations in their team. To avoid emergence of an "always on" culture, they should openly discuss perceived and actual availability expectations within their team and explicitly state that team members are allowed to engage in heterogeneous work-nonwork segmentation behaviors (Mazmanian, 2013). Second, organizations could foster alignment of employees' actual boundary management behavior with their personal preferences by (a) sensitizing employees for their personal boundary management preferences, (b) encouraging them to communicate their preferences within their teams, and (c) facilitating diverse degrees of work-nonwork segmentation among their employees instead of forcing them into certain boundary management behaviors.

To enable nonwork-work integration, organizations could allow their employees to communicate with nonwork contacts and take care of nonwork matters while they work. Flexible work arrangements have the potential to contribute to reduced work-nonwork conflict (Allen et al., 2013) and may likewise allow for positive nonwork-work spillover. Yet, as nonwork-work integration bares the risk of interruptions that impair task performance, organizations should ask employees to openly discuss availability expectations with their nonwork contacts and find ways to bring those in line with their work responsibilities. For instance, employees could set time frames in which they are unavailable to allow for phases of uninterrupted, focused work.

\section{Limitations and Future Directions}

A limitation of this study is that, while differentiating between supervisor and coworker availability expectations, we do not differentiate between family members and friends for nonwork contacts' availability expectations. Since availability for family matters may be more closely linked to fulfilling responsibilities (Sayah, 2013) than availability for friends, future studies should investigate the availability expectations of these groups separately to gain a more complete picture of how availability expectations are linked to boundary management behavior.

Second, while the present study finds that work-nonwork and nonwork-work segmentation have divergent effects on life balance, the potentially underlying mechanisms of these relationships - namely, inter-domain conflict and positive spillover - need empirical investigation. Future studies should examine the effects of bidirectional boundary management behavior on inter-domain conflict, positive spillover, and life balance to contribute to our understanding of the distinct effects of work-nonwork and nonwork-work segmentation. Moreover, it might be fruitful for future research to explore if and how the suggested mechanisms and effects extend to other, job-related outcomes. While our findings as well as results of other studies hint at the beneficial effects of higher work-nonwork segmentation (e.g., Carlson et al., 2015; Wepfer et al., 2018) and lower nonwork-work segmentation on well-being, the relationship with job-related constructs such as work engagement or productivity might be different and even vary over time. For example, engaging in low worknonwork segmentation and high nonwork-work segmentation might allow for higher levels of productivity and performance in the short run, yet result into impaired well-being, and consequently low performance in the long term.

Third, while we separated measurement of availability expectations and boundary management preferences from that of all endogenous variables by 6 weeks to reduce common method bias (Podsakoff et al., 2012), future research could additionally measure boundary management behavior and well-being at different points in time to examine the former's enduring effects on individual-level outcomes. Moreover, while several researchers suggested that perceptions of balance might influence other work, family, and health-related outcomes (Greenhaus \& Allen, 2011; Wayne et al., 2017), our study design does not allow for clear causal inference, as we measured life balance, exhaustion, and life satisfaction at the same point in time. Future research could substantiate the role of life balance as a mediator between processes at the interface of work and personal life and more general outcomes related to well-being by temporally separating their measurement. In this context, it is important to note that life balance or related balance constructs can also be considered as outcome variables in their own right, but establishing their link to more general work, family, and healthrelated outcomes further emphasizes the relevance of such balance constructs for individual functioning and well-being.

Lastly, this study relies on self-report data from employees of four organizations. By additionally collecting data from relevant others in both work and nonwork domains, and across various organizations, future studies could gain fruitful insights into how the results generalize beyond the self-reports of the sample in the present study. In particular, 
research could include perceived availability expectations and "true" availability expectations as reported by supervisors, coworkers, family members, and friends themselves. This approach would enable to capture differences between perceived and "true" expectations and their relative effects.

\section{Conclusion}

Our study shows that availability expectations of work and nonwork contacts shape how employees actually manage the boundaries of work and nonwork domains, beyond other well-established antecedents. We also find that worknonwork and nonwork-work segmentation behavior have divergent effects on well-being, indicating that asymmetrical boundary management might be beneficial. Further, our findings underline the importance of enabling employees, especially those with high work-nonwork segmentation preferences, to align their actual boundary management behavior with their preferences. Together, our study provides a comprehensive, yet differentiated research framework based on theoretical considerations, adding to our holistic understanding of the drivers and consequences of boundary management behavior in the age of ICT-enabled availability.

Supplementary Information The online version contains supplementary material available at https://doi.org/10.1007/s10869-021-09768-x.

\begin{abstract}
Acknowledgements This research was part of Social Link, a project funded by the LOEWE Program of Excellence in Research, Hessen, Germany. We thank the associate editor, Russell A. Matthews, and our anonymous reviewers for their valuable feedback to improve this manuscript. We also thank Ruth Maria Stock for her helpful feedback throughout this project.
\end{abstract}

Funding Open Access funding enabled and organized by Projekt DEAL.

Open Access This article is licensed under a Creative Commons Attribution 4.0 International License, which permits use, sharing, adaptation, distribution and reproduction in any medium or format, as long as you give appropriate credit to the original author(s) and the source, provide a link to the Creative Commons licence, and indicate if changes were made. The images or other third party material in this article are included in the article's Creative Commons licence, unless indicated otherwise in a credit line to the material. If material is not included in the article's Creative Commons licence and your intended use is not permitted by statutory regulation or exceeds the permitted use, you will need to obtain permission directly from the copyright holder. To view a copy of this licence, visit http://creativecommons.org/licenses/by/4.0/.

\section{References}

Ajzen, I. (1991). The theory of planned behavior. Organizational Behavior and Human Decision Processes, 50, 179-211.
Allen, T. D., Johnson, R. C., Kiburz, K. M., \& Shockley, K. M. (2013). Work-family conflict and flexible work arrangements: Deconstructing flexibility. Personnel Psycholgy, 66(2), 345-376.

Ashforth, B. E., Kreiner, G. E., \& Fugate, M. (2000). All in a day's work: Boundaries and micro role transitions. Academy of Management Review, 25(3), 472-491.

Basile, K., \& Beauregard, T. A. (2021). Oceans apart: Work-life boundaries and the effects of an oversupply of segmentation. The International Journal of Human Resource Management, 32(5), 1139-1170.

Baumeister, R. F., \& Leary, M. R. (1995). The need to belong: Desire for interpersonal attachments as a fundamental human motivation. Psychological Bulletin, 117(3), 497-529.

Bogaerts, Y., De Cooman, R., \& De Gieter, S. (2018). Getting the work-nonwork interface you are looking for: The relevance of work-nonwork boundary management fit. Frontiers in Psychology, 9. Article, 1158, 1-12.

Boswell, W. R., \& Olson-Buchanan, J. B. (2007). The use of communication technologies after hours: The role of work attitudes and work-life conflict. Journal of Management, 33(4), 592-610.

Braukmann, J., Schmitt, A., Ďuranová, L., \& Ohly, S. (2018). Identifying ICT-related affective events across life domains and examining their unique relationships with employee recovery. Journal of Business and Psychology, 33, 529-544.

Carlson, D. S., Kacmar, K. M., Zivnuska, S., \& Ferguson, M. (2015). Do the benefits of family-to-work transitions come at too great a cost? Journal of Occupational Health Psychology, 20(2), 161-171.

Carmeli, A., \& Schaubroeck, J. (2007). The influence of leaders' and other referents' normative expectations on individual involvement in creative work. The Leadership Quarterly, 18(1), 35-48.

Casper, W. J., Vaziri, H., Wayne, J., DeHauw, S., \& Greenhaus, J. H. (2018). The jingle-jangle of work-nonwork balance: A comprehensive and meta-analytic review of its meaning and measurement. Journal of Applied Psychology, 103(2), 182-214.

Chesley, N. (2014). Information and communication technology use, work intensification and employee strain and distress. Work, Employment and Society, 28(4), 589-610.

Cheung, G. W., Cooper-Thomas, H. D., Lau, R. S., \& Wang, L. C. (2021). Testing moderation in business and psychological studies with latent moderated structural equations. Journal of Business and Psychology. https://doi.org/10.1007/ s10869-020-09717-0

Chiaburu, D. S., \& Harrison, D. A. (2008). Do peers make the place? Conceptual synthesis and meta-analysis of coworker effects on perceptions, attitudes, ocbs, and performance. Journal of Applied Psychology, 93(5), 1082-1103.

Clark, S. C. (2000). Work/family border theory: A new theory of work/ family balance. Human Relations, 53(6), 747-770.

Cohen, J., Cohen, P., West, S. G., \& Aiken, L. S. (2003). Applied multiple regression/corrleation analysis for the behavioral sciences (3rd ed.). Erlbaum.

Davenport, T. H. (2005). Thinking for a living: How to get better performances and results from knowledge workers. Harvard Business School Press.

Demerouti, E., Bakker, A. B., Nachreiner, F., \& Schaufeli, W. B. (2001). The job demands-resources model of burnout. Journal of Applied Psychology, 86(3), 499-512.

Derks, D., Bakker, A. B., Peters, P., \& van Wingerden, P. (2016). Workrelated smartphone use, work-family conflict and family role performance: The role of segmentation preference. Human Relations, 69(5), 1045-1068.

Derks, D., van Duin, D., Tims, M., \& Bakker, A. B. (2015). Smartphone use and work-home interference: The moderating role of 
social norms and employee work engagement. Journal of Occupational and Organizational Psychology, 88(1), 155-177.

Direnzo, M. S., Greenhaus, J. H., \& Weer, C. H. (2015). Relationship between protean career orientation and work-life balance: A resource perspective. Journal of Organizational Behavior, 36(4), 538-560.

Edwards, J. R., Caplan, R. D., \& Harrison, R. V. (1998). Person-environment fit theory: Conceptual foundations, empirical evidence, and directions for future research. In C. L. Cooper (Ed.), Theories of organizational stress (pp. 28-67). Oxford University Press.

Edwards, J. R., \& Rothbard, N. P. (1999). Work and family stress and well-being: An examination of person-environment fit in the work and family domains. Organizational Behavior and Human Decision Processes, 77(2), 85-129.

Fenner, G. H., \& Renn, R. W. (2010). Technology-assisted supplemental work and work-to-family conflict: The role of instrumentality beliefs, organizational expectations and time management. Human Relations, 63(1), 63-82.

Fishbein, M., \& Ajzen, I. (2010). Predicting and changing behavior: The reasoned action approach. Psychology Press.

Frone, M. R., \& Rice, R. W. (1987). Work-family conflict: The effect of job and family involvement. Journal of Occupational Behavior, $8(1), 45-53$.

Frone, M. R., Russell, M., \& Cooper, M. L. (1992). Antecedents and outcomes of work-family conflict: Testing a model of the workfamily interface. Journal of Applied Psychology, 77(1), 65-78.

Gadeyne, N., Verbruggen, M., Delanoeije, J., \& De Cooman, R. (2018). All wired, all tired? Work-related ICT-use outside work hours and work-to-home conflict: The role of integration preference, integration norms and work demands. Journal of Vocational Behavior, 107, 86-99.

Greenhaus, J. H., \& Allen, T. D. (2011). Work-family balance: A review and extension of the literature. In J. C. Quick \& L. E. Tetrick (Eds.), Handbook of occupational health psychology (pp. 165-183). American Psychological Association.

Hecht, T. D., \& Allen, N. J. (2009). A longitudinal examination of the work-nonwork boundary strength construct. Journal of Organizational Behavior, 30(7), 839-862.

Kanungo, R. N. (1982). Measurement of job and work involvement. Journal of Applied Psychology, 67(3), 341-349.

Klein, A., \& Moosbrugger, H. (2000). Maximum likelihood estimation of latent interaction effects with the LMS method. Psychometrika, 65(4), 457-474.

Kossek, E. E., \& Lautsch, B. A. (2012). Work-family boundary management styles in organizations: A cross-level model. Organizational Psychology Review, 2(2), 152-171.

Kossek, E. E., Ruderman, M. N., Braddy, P. W., \& Hannum, K. M. (2012). Work-nonwork boundary management profiles: A personcentered approach. Journal of Vocational Behavior, 81, 112-128.

Kreiner, G. E. (2006). Consequences of work-home segmentation or integration: A person-environment fit perspective. Journal of Organizational Behavior, 27(4), 485-507.

Kubicek, B., \& Tement, S. (2016). Work intensification and the workhome interface: The moderating effect of individual work-home segmentation strategies and organizational segmentation supplies. Journal of Personnel Psychology, 15(2), 76-89.

Lazarus, R. S., \& Folkman, S. (1984). Stress, appraisal, and coping. Springer.

Maertz, C. P., \& Boyar, S. L. (2011). Work-family conflict, enrichment, and balance under "levels" and "episodes" approaches. Journal of Management, 37(1), 68-98.

Maslach, C., Jackson, S. E., \& Leiter, M. P. (1996). MBI manual (3rd ed.). Consulting Psychologists Press.

Matthews, R. A., Barnes-Farell, J. L., \& Bulger, C. A. (2010). Advancing measurement of work and family domain boundary characteristics. Journal of Vocational Behavior, 77(3), 447-460.
Matthews, R. A., Wayne, J. H., \& McKersie, S. J. (2016). Theoretical approaches to the study of work and family: Avoiding stagnation via effective theory borrowing. In T. D. Allen \& L. T. Eby (Eds.), Oxford handbook of work and family (pp. 23-35). Oxford University Press.

Matusik, S. F., \& Mickel, A. E. (2011). Embracing or embattled by converged mobile devices? Users' experiences with a contemporary connectivity technology. Human Relations, 64(8), 1001-1030.

Mazmanian, M. (2013). Avoiding the trap of constant connectivity: When congruent frames allow for heterogeneous practices. Academy of Management Journal, 56(5), 1225-1250.

Mazmanian, M., Orlikowski, W. J., \& Yates, J. (2013). The autonomy paradox: The implications of mobile email devices for knowledge professionals. Organization Science, 24(5), 1337-1357.

Methot, J. R., \& LePine, J. A. (2016). Too close for comfort? Investigating the nature and functioning of work and non-work role segmentation preferences. Journal of Business and Psychology, $31,103-123$.

Morgeson, F. P., \& Humphrey, S. E. (2006). The Work Design Questionnaire (WDQ): Developing and validating a comprehensive measure for assessing job design and the nature of work. Journal of Applied Psychology, 91(6), 1321-1339.

Muthén, L. K., \& Muthén, B. O. (1998-2017). Mplus User's Guide $\left(8^{\text {th }}\right.$ ed.). Muthén and Muthén.

Netemeyer, R. G., Boles, J. S., \& McMurrian, R. (1996). Development and validation of work-family conflict and family-work conflict scales. Journal of Applied Psychology, 81(4), 400-410.

Nippert-Eng, C. (1996). Calendars and keys: The classification of "home" and "work." Sociological Forum, 11(3), 563-582.

Palm, E., Seubert, C., \& Glaser, J. (2020). Understanding employee motivation for work-to-nonwork integration behavior: A reasoned action approach. Journal of Business and Psychology, 35, 683-696.

Park, Y., \& Jex, S. M. (2011). Work-home boundary management using communication and information technology. International Journal of Stress Management, 18(2), 133-152.

Park, Y., Fritz, C., \& Jex, S. M. (2011). Relationships between workhome segmentation and psychological detachment from work: The role of communication technology use at home. Journal of Occupational Health Psychology, 16(4), 457-467.

Pavot, W., \& Diener, E. (1993). Review of the satisfaction with life scale. Psychological Assessment, 5(2), 164-172.

Piszczek, M. E. (2017). Boundary control and controlled boundaries: Organizational expectations for technology use at the workfamily interface. Journal of Organizational Behavior, 38(4), 592-611.

Podsakoff, P. M., MacKenzie, S. B., \& Podsakoff, N. P. (2012). Sources of method bias in social science research and recommendations on how to control it. Annual Review of Psychology, 63(1), 539-569.

Powell, G. N., \& Greenhaus, J. H. (2010). Sex, gender, and the work-tofamily interface: Exploring negative and positive interdependencies. Academy of Management Journal, 53(3), 513-534.

Richter, P., Hemmann, E., Merboth, H., Fritz, S., Hansgen, C., \& Rudolf, M. (2000). Das Erleben von Arbeitsintensität und Tätigkeitsspielraum - Entwicklung und Validierung eines Fragebogens zur orientierenden Analyse (FIT). Zeitschrift Für Arbeits- Und Organisationspsychologie, 44, 129-139.

Sayah, S. (2013). Managing work-life boundaries with information and communication technologies: The case of independent contractors. New Technology, Work and Employment, 28(3), 179-196.

Valcour, M. (2007). Work-based resources as moderators of the relationship between work hours and satisfaction with work-family balance. Journal of Applied Psychology, 92(6), 1512-1523.

Wajcman, J., \& Rose, E. (2011). Constant connectivity: Rethinking interruptions at work. Organization Studies, 32(7), 941-961. 
Wayne, J. H., Butts, M. M., Casper, W. J., \& Allen, T. D. (2017). In search of balance: A conceptual and empirical integration of multiple meanings of work-family balance. Personnel Psychology, 70(1), 167-210.

Wayne, J. H., Matthews, R., Crawford, W., \& Casper, W. J. (2020). Predictors and processes of satisfaction with work-family balance: Examining the role of personal, work, and family resources and conflict and enrichment. Human Resource Management, 59, $25-42$.

Wepfer, A. G., Allen, T. D., Brauchli, R., Jenny, G. J., \& Bauer, G. F. (2018). Work-life boundaries and well-being: Does work-to-life integration impair well-being through lack of recovery? Journal of Business and Psychology, 33, 727-740.

Wright, T. A., \& Huang, C.-C. (2012). The many benefits of employee well-being in organizational research. Journal of Organizational Behavior, 33(8), 1188-1192.

Publisher's Note Springer Nature remains neutral with regard to jurisdictional claims in published maps and institutional affiliations. 